\title{
La reestructuración institucional de la Administración Pública. Un punto prioritario en la agenda modernizadora
}

n estos días está de moda hablar de la modernización del Estado dentro y
fuera de nuestro país. En el ámbito nacional, la comisionada presidencial
para la modemización, licenciada Ana Cristina Sol, ha expuesto recientemente a la prensa los principales objetivos perseguidos por la reforma que son: reestructuración institucional, capacitación de los servidores públicos, simplificación de los procedimientos, descentralización, modemización del sistema de adminislración financiera y reforma de la previsión social. Es necesario suponer que estos objetivos coinciden con los del Programa de Modemización del Sector Público (PMSP), contenido en un documento que no ha sido difundido en el ámbito intemol.

Para apoyar y asistir técnicamente esa agenda modernizadora, el Banco Internacional de Reconstrucción y Fomento (BIRF) firmó un contrato de préstamo con el Gobiemo de la República por la "módica" cantidad de veinticualro millones de dólares2. La suma no me parece nada despreciable, sobre todo si tenemos en cuenta que se va a destinar a sufragar exclusivamente la asistencia técnica para implementar el programa modemizador. En cualquier caso, los objetivos del contrato se expresan claramente en el anexo 2 del Convenio, y se concretan en los siguientes puntos: reestructuración y desburocratización institucional, administración de recursos financieros, y privatización y participación del sector privado en la prestación de servicios públicos.

En este oportunidad me centraré en uno de los temas propuestos, la reestructuración institucional de la administración. 


\section{La necesidad de una reestructuración institucional y la descentralización}

Tal y como lo señala el Convenio de préstamo firmado con el BIRF, una de las reformas que ha emprendido el Gobierno de la República es la "reorganización" de los organismos y unidades con que cuenta la Administración Pública.

Me interesa en este punto llamar la atención sobre las posibles dificultades con las que se van a encontrar los profesionales que asuman esta ardua labor.

Uno de los problemas principales de la Administración pública en nuestro país es que pareciera haber sido organizada sin ton ni son, que responde siempre a necesidades coyunturales. Esta no es la primera vez que se quieren reorganizar los distintos órganos y unidades que componen la Administración. Pueden citarse, cuando menos, dos experiencias previas. En 1984 se creó la Comisión de racionalización del gasto público y reestructuración administrativa3. Esta Comisión tenía como finalidad estudiar la autofinanciación de los servicios públicos, determinar cómo controlar más eficazmente la administración de las plazas disponibles de forma que se pudieran satisfacer las necesidades y actuar con más eficiencia, e intentar reducir los trámiles, solicitudes y formularios que los administrados han de llenar ante las diversas instancias gubernativas.

Más tarde, con un alcance más limitado, aparece la Unidad coordinadora del proyecto de mejoramiento de los servicios públicos ${ }^{4}$, destinataria en aquella oportunidad de los fondos del Convenio de donación para el mejoramiento de los servicios públicos, ratificado por decreto el 20 de septiembre de 19895. En efecto, el propósito perseguido con la creación de esta unidad era más restringido puesto que sólo tenía que coordinar las acciones y definir los lineamientos destinados a mejorar los servicios en materia de agua potable y saneamiento a nivel nacional.

Hasta donde he podido investigar, ninguna de las comisiones publicó las conclusiones a que llegaron. No deja de ser una tristeza, sobre lodo en el caso de la primera, que estuvo funcionando cuatro años, sin que sepamos qué ha ocurrido con su trabajo. No sabemos qué hiceron, qué resultados obtuvieron, y mucho menos, si algunas reestructuraciones que se han efecluado en el seno de la Administración obedecieron a sus concretas y particulares recomendaciones. Lo que ahora interesa resaltar es que el tema de la reforma administrativa, reforma que es sentida como una necesidad por todos, pero que ha tropezado con no pocos obstáculos, no es tan novedodo como aparenta ser. Al menos deberíamos preguntamos por qué han resultados fallidos los intentos anteriores.

En cualquier caso, y contemplado el problema de cara al futuro, parece que la reeslructuración de la Administración que se quiere impulsar necesita contar previamente con un diagnóstico del marco nomativo regulador de las instituciones que se van a reformar. 


\section{La Administración Pública}

Desde la perspectiva jurídica, una premisa que hay que tener en cuenta es que la Administración Pública en nuestro país no tiene personalidad jurídica propia e independiente de la del Estado. Está constiluida por un conjunto de entes, órganos y unidades de los que solamente algunos han sido personificados6. Según el artículo 2 de la Ley de la jurisdicción contencioso-administrativa?, conforman la Administración Pública en el país: el Organo Ejecutivo, sus dependencias, las autónomas y semiautónomas, los gobiernos locales, y, excepcionalmente, los Poderes Legislativo y Judicial, y organismos independientes cuando dicten actos administrativos.

\subsection{La Administración central: Organo Ejecutivo e instituciones autónomas}

Comencemos por el propio Organo Ejecutivo. Un simple vistazo a su organización revela el caos normativo en que hemos estado funcionando y lo lejos que está de completarse su regulación. Tal y como establece la ConstituciónB, corresponde al Consejo de Ministros la potestad de dictar el Reglamento intemo del Poder Ejecutivo. En ejercicio de ese mandato, el 18 de abril de 1989 se aprueba el mencionado reglamento9, El artículo 80 del mismo obligaba a los distintos ministros a desarrollar y aprobar los marcos organizatorios de cada Secretaría de Estado en el plazo de 180 días a contar desde la entrada en vigor del decreto. Lejos de ello, ocho años después, algunos ministerios carecen todavía de regulación, la dictaron fuera del plazo establecido, o cuentan con ella porque ha sido aprobada por la asamblea. En este último caso, la intervención legislativa ha supuesto la congelación del rango de la norma, de forma que se ha impedido toda intromisión posterior del poder reglamentario. Como resultado de ello, si la Administración quiere después reestructurarse intemamente, necesariamente ha de contar para ello con la asamblea, pues sólo una ley puede derogar otra ley anterior. El Ministerio de Trabajo y Previsión Social, por ejemplo, ha sido regulado en una norma con rango de ley - Ley de organización y funciones del sector trabajo y previsión social10-, y por ello tendrá que volver a ser regulado en el futuro por otra ley formal. O el caso del Ministerio de Hacienda, que no tiene reglamento ni ley que regule su organización intema, sino que hay un conjunto de leyes que crean las potestades que tiene encomendadas y distribuyen diferentes competencias entre sus órganos. Así, por ejemplo: la Ley Orgánica de la Dirección General de Impuesios Internos 11, la Ley de Organización y funcionamiento del Tribunal de Apelaciones de los Impuestos Internos 12, o la Ley Orgánica de la Administración Financiera del Estado13.

$\mathrm{Ni}$ el administrado ni el propio Organo Ejecutivo saben concretamente cómo está éste realmente estruclurado. A cualquier observador le resulta difícil determinar quien tiene la compelencia para ejercer las potestades que el 
ordenamiento jurídico le ha encomendado. $Y$ aunque pareciera innecesario decirlo, hay que contar con la nomativa vigente, pues a uno no deja de sorprenderle que en ocasiones la propia Administración no sepa que tal o cual norma ha sido derogada. Se derogan leyes y quedan vigentes sus reglamentos de ejecución o, lo que es peor, se incluyen en reglamentos de organización normas que obligan a los particulares, cuando se sabe que éstos no pueden tener efectos ad extra. La ejecución de las leyes no puede ser objeto de regulación en un reglamento de esta naturaleza. Sirva como ejemplo el art. 2 del Reglamento intemo del Ministerio de Salud Pública y Asistencia Social14.

Distinto es el caso de las Instiluciones Autónomas, entes administrativos que están especializados en razón del servicio que prestan. Suelen tener encomendado la gestión de un fin eminentemente público y suponen la expresión máxima de la descentralización por servicios. Las Instiluciones autónomas sí cuentan con personalidad jurídica propia, y, a efectos de su incardinación en la estructura organizativa de la Administración centralizada, suelen estar adscritas a un Ministerio determinado. Es lo que la doctrina ha denominado "lutela sobre los entes descentralizados" y que supone un cierto poder de vigilancia, más débil que en el caso de estrictas relaciones de jerarquía. En efecto, el art. 16, númeral décimo del Reglamento Interno del Organo Ejecutivo, establece la competencia de los ministros para "supervisar y controlar las instituciones autónomas que por ley estén supeditadas a su dependencia e informar al Presidente de la República semestralmente, sobre la situación general de las mismas"I5.

La descentralización no es una técnica nueva en materia de organización administrativa, lejos de ello constituye una forma tradicional de prestación de los servicios. Como técnica organizativa ha sido muy cuestionada por el Gobiemo al impulsar sus planes de privatización. Ahora se esgrime como bandera de la modernización. ¿No son ANTEL y CEL -entre muchos otros- entes descentralizados? ¿Por qué se privatizan entonces?

Se ha argumentado que no funcionan eficazmente y que, además, no corresponde al Estado asumir la prestación de servicios públicos económicos. ¿Por qué vender ahora la panacea de la descentralización? ¿Hay algún orden y concierto en todo esto?

De hecho, los últimos gobiemos de ARENA han optado casi invariablemente por esta forma descentralizada de gestión. Véase el caso del Fondo de Inversión Social16, o los más recientes del Fondo Nacional del Medio Ambiente17, la Corporación Salvadoreña de Turismole, etc.

Un caso especial lo constituyen las entidades semiautónomas que menciona la Ley de la jurisdicción contenciosa. Conceptualmente no existen como categoría independiente: o el ente personificado está dotado de verdadera autonomía, en cuyo caso nos encontraremos en presencia de una Inslitución Autónoma, o estamos 
en presencia de un órgano simplemente desconcentrado. La desconcentración supone que la autoridad central atribuye ciertas funciones a alguna dependencia y ésta las ejerce con cierta libertad, aunque dependen jerárquicamente del órgano central. En este caso, la descentralización es menor pues los órganos desconcentrados no tienen ni personalidad jurídica propia ni patrimonio independiente.

Las denominaciones que reciben estos órganos recuerdan en mucho casos las de las Instituciones Autónomas y, sin embargo, una lectura de los decretos de creación nos revela claramente que no estamos en presencia de una auténtica descentralización por servicios. Es el caso de la Superintendencia del Sistema Financiero, entidad desconcentrada del Banco Central de Reserva. Por ello, la Asamblea Legislativa actuó correctamente cuando, en la reciente siluación de captación ilegal de fondos, dirigió la interpelación al Presidente del BCR y no contra el Superintendente. O, el caso del Consejo Nacional de Trabajo, dependencia consultiva del Ministerio de Trabajo y Previsión Social.

Estas unidades "semiautónomas" se han creado con los más variables propósitos. La mayoría de las veces se han instituido para cumplir funciones de colaboración interinstitucional, o bien, para asesorar a otro órgaNo En el seno del Poder Ejecutivo existen varias comisiones conformadas por la casi totalidad de los ministros, de forma que no deja de sorprender su "desconcentración". Esto, lejos de aliviar el trabajo del Consejo al que correspondía inicialmente la competencia, supone una sobrecarga adicional para sus integrantes. ¿Por qué no ventilar la política alimentaria o la de la población en el seno del órgano rector de la política nacional? Lo que se hace, en realidad, es crear una nueva unidad administrativa para descargar de trabajo a otra, pero el propósito falla si quienes la integran son las mismas personas, de forma que no se entiende qué alivo de funciones pueda suponer.

En olras ocasiones nos encontramos con otro fenómeno: cambio de nombre y mantenimiento de funciones. Se crean las dependencias y con el transcurso del tiempo se sustituyen por olras a las que se atribuyen exactamente los mismos cometidos que desempeñaban las primeras, persiguiendo los mismos lines. Tampoco en este caso se entiende la razón de esa innecesaria sustilución, pues nadie podrá creer que el simple cambio de nombre pueda conllevar una mejor gestión. Este es el caso del Comité Nacional del Medio Ambiente19, creado en 1974 para paliar las alarmantes consecuencias que estaba ocasionando "el aumento poblacional, el creciente desarrollo industrial, el aumento del número de vehículos automotores, incineración de desechos, la presencia en el ambiente de maleria particularizada, gases, cenizas y polvo nalural". En 1990, casi veinte años después, es sustituido por el Consejo Nacional del Medio Ambiente20, y, en 1994, por la Secretaría Ejecutiva adscrita al Ministerio de Agricultura. Sólo hasła la firma de los Acuerdos de Reconversión de Deuda con Canadá y Estados Unidos se 
encomiendan competencias ejecutivas a este organismo, que hasta entonces no hacía más que proponer políticas para la protección del medio ambiente que nunca fueron ejecutadas

Todo ello hace o debería hacer reflexionar sobre los efeclos que tal dispersión administrativa tiene sobre la ejecución de las políticas.

\subsection{La administración local}

Por último nos referiremos brevernente a las municipalidades. La Constitución reconoce la autonomía municipal en lo "económico, en lo técnico y en lo administrativo" (art. 203) y esta autonomía se traduce en la reserva de un ámbito de competencias municipales, ámbito especificado en el artículo 204.

Las municipalidades no son Asambleas Legislativas "en pequeño". Las municipalidades son Gobiernos locales, Administraciones públicas. La relación que une a las Alcaldías con la Administración central no es una relación de jerarquía, sino que sólo puede ser explicada desde el principio de separación, porque "separados están los campos en los que una y otra pueden operar"21. En efecto, el Estado salvadoreño ha adoptado una forma de descentralización por territorio, atribuyendo a las municipalides la prestación de aquellos servicios más inmediatos para su población, por ejemplo, el servicio de aseo, barrido de calles, recolección y disposición final de basura, mercados, tiangues y mataderos, cementerios y servicios funerarios, etc. En estos ámbilos no puede entrometerse la administración central, salvo en el caso de que la municipalidad respecliva celebrase un contrato de colaboración con ella.

Sólo distribuyendo y separando los respectivos ámbitos de competencia puede explicarse el principio de autonomía. La administración municipal, contrario a lo que suele creerse, no está subordinada al Poder Ejecutivo. Es, simplemente, algo distinto y separado de aquélla.

Debemos entonces preguntamos seriamente si realmente se conoce la organización de nuestra propia Administración. Una lectura atenta del propísimo Diario Oficial apunta lo contrario. El Diario Oficial cuenta con cinco secciones: Organo Legislativo, Organo Ejecutivo, Organo Judicial, Instituciones Autónomas y Carteles oficiales. Pues bien, las municipalidades están incluidas como inslituciones Autónomas. Se sabe que las municipalidades no son instituciones autónomas, sino entes territoriales inferiores, es decir, una forma descentralizada por territorio. A su vez los municipios pueden adoptar la forma de descentralización por servicios, encomendando a alguna institución aulónoma municipal su prestación. Esta facultad está expresamente recogida en el artículo 14 del Código municipal22. 


\section{El principio de colaboración}

En muchos órganos, unidades e instituciones que conforman la Administración puede observarse una tendencia a la concertación institucional, solapada con ínfulas de coordinación y que, so pretexto de la misma, carga a los órganos de la Administración de representatividad lo que sin duda dificulta en extremo su operatividad ejecutiva real. No hay más que echar un vistazo a la conformación de algunos organismos: el caso del CODEMET23, regulado en la Ley de desarrollo y ordenamiento territorial del área melropolitana de San Salvador, o del futuro Sistema Nacional del Medio Ambiente en el que participan un sinnúmero de órganos e instituciones. No me cabe duda que hay una necesidad imperiosa de coordinar, pero ésta nunca podrá llevarse a cabo reproduciendo en la gestión administrativa diaria las lentitudes más propias y necesarias de la planificación y proposición políticas. Sirva de reflexión la famosa frase del administrativista español Alejandro Oliván: "para deliberar como para juzgar son buenos los muchos; para ejecutar, uno solo"24 .

De aquí que el diagnóstico de la organización administrativa actual debiera, pues, servir para planificar todas las acciones de reestrucluración que se aborden, asi como para prever las dificultades que esta tarea conlleva y que permitan, a la posire, la descentralización que pretende la modernización. Ese diagnóstico debería comprender un análisis de los aciertos y desaciertos de los intentos de reforma pasados. Ello permitiría crear una secuencia lógica que permita el cambio normativo y facilite la adaptación a ese cambio.

Como corolario de lo anterior, no queda sino expresar la sólida convicción de que es imperativo y urgente emprender una reorganización de la Administración Pública. Justamente por ello es que aquí se advierte la necesidad de hacerlo de una manera orgánica y estructural, subrayando el hecho de que una modificación en una instancia administrativa obliga necesariamente a considerar las consecuencias que ocasionará en el funcionamiento de otras con las que pudiera estar relacionada.

\section{Notas}

1. El convenio con el BIRF establece que el documento es de mayo de 1996.

2. El convenio de préstamo fue ratificado por la Asamblea Legislativa por Decreto Legislativo No 938, del 15 de enero de 1977, publicado en El Diario Oficial del 19 de febrero.

3. Decreto ejecutivo del 28 de julio de 1984 publicado en El Diario Oficial del 30 de julio de 1984. Fue derogada el 16 de marzo de 1988, Diario Oficial del 17 de marzo de 1988.

4. Acuerdo Ejecutivo del 17 de enero de 1990 , Diario Oficial del 19 de oclubre de 1993. 
5. Publicado en El Diario Oficial, 8 noviembre de 1989.

6. Es el caso de los municipios y de las instituciones autónomas.

7. Decreto Legislalivo No 81, 14 de noviembre de 1978, publicado en El Diario Oficial del 19 de diciembre.

8. Arr. 167 de la Constitución: "Corresponde al Consejo de Ministros: 1. Decretar el Reglamento Interno del Organo Ejeculivo y su propio reglamento.

9. Decreto Ejecutivo No 24, publicado en El Diario Oficial del 18 de abril de 1989.

10. Decreto Legislativo No 682 del 11 de abril de 1996. Publicado en El Diario Oficial del 3 de mayo del mismo año.

11. Decreto Legislativo No 451 del 1 de marzo de 1990. El Diario Oficial del 7 de marzo.

12. Decreto Legislativo No 135 del 21 de diciembre de 1991, publicado en El Diario Oficial de esa misma fecha.

13. Decreto Legislativo No 716 del 23 de mayo de 1996. El Diario Oficial del 11 de enero de 1996.

14. Art. 2 del Reglamento Interno del Ministerio de Salud Pública y Asistencia Social: "Toda persona natural o jurídica queda sujela a las prescripciones de esle reglamento y demás disposiciones aplicables que no lo contaríen..". Decreto ejecutivo No 25 , de 2 de mayo de 1989, publicado en El Diario Oficial de la misma fecha.

15. Esa tutela no ha sido manifestada claramente en todas las ocasiones. Sin embargo, vale la pena citar algunos ejemplos. La Corporación Salvadoreña de Turismo (CORSATUR) depende del Ministerio de Economía al que debe rendirle informes y estados linacieros (art. 13. d de su ley de creación). La Comisión Ejecutiva Porluaria Autónoma (CEPA) y el Fondo Nacional de la Vivienda Popular (FONAVIPO) están adscritas al Minislerio de Obras Públicas. El Fondo de Inversión Social (FISS) dependía del Ministerio de Planificación y Coordinación del Desarrollo Económico y Social (art. 30 del Decreto Legislativo de 31 de octubre de 1990), lambién el Fondo Salvadoreño para estudios de preinversión (FOSEP). El Instiluto Salvadoreño del Seguro Social (ISSS) está adscrilo al Ministerio de Trabajo y Previsión Social. La tutela es mayor en algunos casos que en otros. Las enlidades que gozan de mayor autonomía así lo declaran expresamente, por cjemplo, la Superintendencia Gencral de Energía y Telecomunicaciones "que se relacionará con los órganos del Estado a través del Ministerio de Economia, exclusivamente para efectos presupucstarios" (art. 3).

En otras ocasiones se puede deducir de quién dependen, pues un Ministro en concreto ocupa la presidencia de su órgano director y ostenta de este modo la facultad de convocar a los demás.

16. Ley de creación del Fondo de Inversión Social de El Salvador, 31 de octubre de 1990. El Diario Oficial del 16 de noviembre de 1990.

17. Ley del Fondo ambiental de El Salvador, 16 de junio de 1994. El Diario Oficial del 26 de junio del mismo año.

18. Ley de la Corporación Salvadorcña de Turismo, Decreto Legislativo del 25 de julio de 1996; El Diario Oficial del 23 de agosto del mismo año.

19. Decreto No 18 del 21 de cnero de 1974. El Diario Oficial del 6 de febrero de esc mismo año. 
20. Decrelo No 73 del 18 de diciembre de 1990. El Diario Oficial, 14 de enero de 1991. Las causas que dan lugar a la creación de esle organismo son sustancialmente: "el creciente desarrollo industrial, cl aumento del tráfico vehicular, la incincración de desechos, la presencia en el airc atmosférico de materia particularizada, gases, cenizas, polvo nalural. (Considerando I).

21. Garcia de Enterría, Eduardo y Fernández, Tomás Ramón, Curso de Derecho Administrativo, Editorial Civitas, Madrid, 1980.

22. Art. 14 del Código municipal: "Los Municipios solos o en unión de otros, podrán acordar la creación de entidades descentralizadas con o sin autonomía, para la rcalización de determinados fines municipales." La Administración Pública local puede prestar los servicios que tiene encomendados directamente, por sí o a través de instituciones autónomas, o indirectamente, creando al efecto socicdades de cconomía mixta (art. $7 \mathrm{dcl}$ Código Municipal).

23. El Consejo de Desarrollo Metropolitano (CODEMET) es el organismo político destinado a coordinar las accciones urbanísticas en cl árca metropolitana con el Gobiemo Central. Está integrado por los 14 alcaldes del COAMSS, el Ministro de Planificación y Coordinación del Desarrollo Económico y Social (ya desaparecido), el Ministro de Hacienda, El Ministro de Obras Públicas y el ViceMinistro de Vivienda y Desarrollo Urbano, el Ministro de Salud, el Secrelario Ejecutivo del Conscjo Nacional del Medio Ambienle, los presidentes de ANDA, CEL y ANTEL. Es una oficina de conccrtación y cooperación pero sin facultades cjecutivas (art. 10). Puede proponer al Consejo de Ministros programas y proyectos de inversión pública para el desarrollo del área metropolitana.

24. Citado por Eduardo García de Entcría en La Administración española, Alianza Edilorial, Madrid, 1985. 